Sección Especial 


\title{
EMILIA ESCRIBE EN LA NOCHE
}

\author{
Vernor Muñoz Villalobos
}

Recibido 3-II-2003

Resumen: Los procesos de resolución de conflictos deben pensarse como ejercicios responsables del respeto a las diferencias y a la diversidad, en el contexto de la exigibilidad y la vigencia de los derechos humanos.

Los conflictos son necesarios, si se conciben como una de las fuerzas motivadoras del cambio social, pues fortalecen la creatividad de las relaciones entre las personas.

La premisa de humanización del conflicto sugiere entonces que la posibilidad de atender las desavenencias en forma pacífica se encuentra determinada por modelos de socialización y educación en los que las personas deben conocer y prepararse para negociar, pero también para ejercer plenamente sus derechos y responsabilidades.

En el marco del pensamiento filosófico sobre la existencia y aceptación de los conflictos, resulta imprescindible esperar que el Estado funja como facilitador y promotor de la concertación social.

Gracias al aporte epistemológico que ofrecieron Jean Piaget (1896-1980), María Montessori (1870-1952) y, a partir de ellos, Paulo Freire (1921-1997), la práctica educativa liberadora empieza a vincularse a la construcción de una ciudadanía responsable y proactiva.

Palabras clave: Conflicto, Participación, Mediación, Escuela, Derechos Humanos, Justicia, Interés Superior del Niño.
No entiendo la existencia humana y la necesaria lucha por mejorarla sin la esperanza y sin el sueño.

Paulo Freire Pedagogía de la esperanza

\section{Cuaderno de notas de la maestra Emilia}

Quizás fue casualidad o pura magia del destino; pero después de leer Emilio, de J.J. Rousseau, en un curso de filosofía de la educación, me encontraba sentado en un poyo del parque de La Colina, el barrio donde vivo, intentando reflexionar sobre un trabajo universitario que debía presentar próximamente.

La lectura del texto de Rousseau me tomó algunos días y, consumido en ese libro, me había desligado del conflicto que vivía la comunidad en torno a las demandas de un grupo de niños y niñas nicaragüenses que reclamaban su derecho a la matrícula en la escuela.

Yo pensaba que ese conflicto me era ajeno y que nada tenía que ver con mis obligaciones académicas, hasta que miré en el basurero que se hallaba justo al lado del poyo y encontré este cuaderno de notas, que contiene, con bella letra cursiva, el diario de prisión de una maestra llamada ¡Emilia! 
El contenido del manuscrito demuestra que la manera que tenemos de resolver conflictos es contraria a los principios que teóricamente deberían impulsar los procesos de negociación en los conflictos humanos.

Demuestra también que, lejos de fungir como sustento pedagógico vinculado a la construcción de una ciudadanía responsable y participante en la toma de decisiones, las instituciones y leyes relativas a la resolución de conflictos están determinadas por la inoperatividad del sistema judicial costarricense.

Después de leer el manuscrito que ahora presento a mi profesora, me he quedado sin impulso para elaborar mi trabajo y por eso decidí presentar el diario de la maestra Emilia como mi mejor excusa y mi mayor anhelo hacia la urgente vocación que debemos tener los estudiantes, profesores, y toda la gente que habita en este país.

Una vocación de compromiso y solidaridad es la mejor respuesta a nuestras necesidades. Por esa razón, antes que plagiar el diario de Emilia, prefiero reconocer esta derrota académica y esta victoria en la conciencia, que gracias a ella, me ha hecho crecer en la esperanza y el amor.

\section{Primera noche}

La memoria resiste a las paredes de mi celda, y aunque triste y aunque herida por este encierro infame, las palabras y los sueños me rescatan de largas horas turbias.

Escribo de noche, para no alumbrar la rabia. Cuento mis penas a invisibles duendes, pero grito la verdad de mi inocencia y me redimo en la dignidad de mi esperanza, porque sé que no hay desánimo que pueda al final vencerme, ni juez ni acusador que puedan vulnerar estas ganas de vivir.

Después de todo, ser maestra me ha ayudado a pasar este trago amargo. Pero más aún, ser maestra montessoriana me permite construir este duro aprendizaje, que, sin desearlo, obtengo de los hechos que me dispongo a consignar en este cuaderno.

Desde hace cuatro años enseño en la Escuela del Barrio La Colina, en donde me ocupo de los niños y niñas del segundo grado.

Todo comenzó al iniciarse el curso lectivo de este año, cuando un grupo numeroso de padres y madres de familia protestaban por no encontrar matrícula para sus hijos e hijas, pues la escuela es muy pequeña y no ha logrado crecer frente a la demanda de tantos estudiantes.

El problema se agravó ante la pretensión simultánea de otro grupo grande de familias nicaragüenses que, radicadas en Costa Rica desde hace más de un año, también reivindicaban el derecho a la educación de sus chicos, igualmente rechazados por falta de espacio.

Los padres y madres de familia costarricenses ya habían pagado la cuota voluntaria que se solicita por la matrícula y reprochaban tener mayor derecho que "los extranjeros", alegando que el Ministerio de Educación debía darles preferencia frente a un grupo de niños y niñas "foráneos", que, según ellos, usurpan los bienes institucionales.

Este conflicto me conmovió profundamente, porque, después de todo, el derecho a la educación no podía tutelarse a unos en detrimento de otros, pero principalmente porque ese derecho afectaba a los niños y las niñas, que sufrirían las consecuencias derivadas de un conflicto de autoridades, es decir, de adultos.

Pero, aparte de la escasez de la oferta educativa, el conflicto se agravó por la pugna de intereses entre el grupo de padres y madres costarricenses y nicaragüenses.

Resultaba evidente que, al expresar el antagonismo, tanto los nacionales como los extranjeros reafirmaban su sentimiento de pertenencia y con ello intentaban establecer su identidad: la realidad era que los ticos se valían del argumento nacionalista 
para perjudicar a los “extranjeros" y los nicaragüenses, por su parte, esgrimían todo tipo de razonamientos propios de una población excluida, discriminada y maltratada.

La noción de pertenencia cultural o identidad estaba actuando, en estas circunstancias, como el detonante de mayor potencia, que poco a poco alteró los ánimos, hasta convertir al barrio La Colina en una verdadera zona de combate.

Pancartas, grafitis ofensivos en las paredes y hasta operativos de la policía de migración fueron sólo algunos ejemplos del clima de intolerancia que se vivía en el barrio. También ciertas familias recibían notas anónimas con amenazas de muerte y otras advertencias similares.

El curso lectivo comenzó sin que el conflicto encontrara solución. Finalmente, el director de la escuela, en una medida desesperada, optó por dar matrícula a todos los niños, nicas y ticos, a costa de la capacidad misma de la escuela y de sus maestras; ello tuvo como consecuencia que, en muchos casos, dos niños tuvieran que compartir el mismo pupitre.

Los problemas continuaron. Movidos por el resentimiento, los padres de familia, a pesar de que todos los chicos habían obtenido la matrícula, se enfrascaron en situaciones de alta agresividad, incluidos pleitos callejeros e insultos desmedidos. En virtud de ello, con la anuencia de la dirección, y dada mi formación académica y mi experiencia en estas lides, me decidí a mediar en el conflicto.

Convoqué a los padres y a las madres a una reunión, para analizar la situación con la mayor objetividad posible, pero a la cita acudieron únicamente cuatro furibundos padres costarricenses y otro tanto de también furibundos nicaragüenses, que se postraron frente a frente sin escucharse y sin mostrar ningún respeto mutuo.

Yo sabía que la manera ideal para solucionar el conflicto sería lograr el mejor compromiso posible de todas las personas, y por esta razón opté por insistirles en atender las razones que tenía cada cual frente al problema.

Pero lamentablemente, aquella primera experiencia fue infructuosa, en virtud de varios hechos significativos. Primero, porque tanto los padres costarricenses como los nicaragüenses, mantenían posiciones defensivas e intransigentes, producto de las agresiones que recíprocamente se habían infringido. Debido a esta situación, el resultado que esperaban cada una de las partes, pasaba por una hipotética reparación de agravios que debía materializarse, según dijeron, mediante la expulsión del grupo de niños ticos, o en su caso, nicas.

Uno de los padres costarricenses, un abogado de empinado copete, arremetía contra un taxista nicaragüense, que luego de intercambios de duras frases, hizo ver que también era un profesional, pero que no podía ejercer por encontrarse en situación de ilegalidad migratoria.

—iiFaltaba más!!! — reprochó el abogado. ¿O es que acaso pretende que también le demos trabajo? ¡Usted debería devolverse a su país, con toda su familia!

Esa interpelación terminó de caldear los ánimos de los nicaragüenses y a poco estuve de convertirme en árbitro de boxeo en pleno salón de profesores.

Obviamente, el problema al que prestaban atención no era ya la situación de los niños en la escuela, sino más bien la intolerancia y las dificultades de convivencia entre adultos. Las personalidades, antes que los intereses, eran los protagonistas principales de esta disputa.

Consciente de la situación, me esforcé por tranquilizar los ánimos de los padres de familia.

Sé que cuando los antagonistas comparten actitudes comunes, también pueden compartir cierto grado de entendimiento respecto de la conducta de cada uno, y por lo tanto a veces pueden estar de acuerdo sobre algunas reglas comunes para resolver los problemas. 
Si no encuentran alguna forma de terminar la contienda antes de matarse unos a otros, es signo evidente de la ausencia de un lenguaje común y por lo tanto de la existencia de percepciones de la situación radicalmente diferentes.

Mi preocupación era encontrar ese grado de entendimiento mínimo. Mi temor, en efecto, era que los puntos de vista de estas personas fueran tan radicalmente diferentes, que ningún entendimiento fuese posible.

Tratando de mediar entre dos facciones de enardecidos varones (las madres habían sido excluidas), escuché lo que decían:

-A mi niña la desprecian los tiquillos... -censuraba un padre nicaragüense. Apenas llega a casa se suelta en llanto, porque todos la critican...

-Será porque no sabe comportarse -replicó un costarricense-, porque al menos mi hijo ha aprendido a defenderse de las injusticias. Y por eso no vamos a soportar que se quede sin educación por culpa de ustedes...

Esas dos intervenciones dieron pie, de nuevo, a una retahíla de reproches, que en resumen apuntaban a una cuestión central: no hay escuela para todos.

Obviamente otros temas conflictivos salían a relucir: desde la "pérdida de valores", hasta la cultura culinaria, pero en todo caso se presentaban como efectos de la presencia masiva de nicaragüenses en el país y de la respuesta de los costarricenses a la migración.

Estos temas dificultaban el diálogo y nos impedían abordar la problemática específica, que consistía en las dificultades que tienen todos los niños y niñas para estudiar, por falta de recursos e infraestructura.

Los enemigos no eran los nicas ni los ticos, sino un sistema educativo deficitario.

La escasez de la oferta educativa era el tema principal, pero ninguna de las partes quería aceptarlo y, por esta razón, la situación tendió a agravarse.
Sin embargo, yo también confiaba en la acción que puede tener el desgaste, que acompañado de la insistencia y de la perseverancia frente a la irracionalidad, en estos conflictos suele tener buenos resultados.

Efectivamente, el conflicto no es un proceso que se prolonga indefinidamente, o que subsista sin cambiar, pues con el tiempo y por el efecto de fenómenos externos, muchas veces tiende a desaparecer.

La clave estaba en procurar que en ese camino de desgaste pudiéramos encontrar soluciones razonables y aceptables para todos.

También tenía presente que en el conflicto siempre hay aspectos positivos, que pueden revertirse y revelar a las desavenencias como cuestiones naturales, como fuerzas motivadoras del cambio, con un potencial creativo que pone a funcionar las buenas intenciones.

Desde ese punto de vista, el conflicto es necesario para el crecimiento y la transformación de las personas, por lo que yo fantaseaba con la idea de que al resolver esta situación pudiéramos superar la intolerancia que se esconde detrás de hechos tan dolorosos, especialmente para los niños y las niñas.

Creo que no estamos condenados a resolver nuestras diferencias de manera brutal.

Pese a mis deseos, la reunión finalizó precipitadamente, pues ambos grupos de padres de familia se enfrascaron en discusiones hirientes, de modo que les solicité retirarse, con el compromiso de continuar conversando después.

A la mañana siguiente recibí a mis estudiantes como de costumbre. No obstante, me encontré con que un niño y dos niñas habían llegado a la escuela con moretones en sus brazos.

Se trataba de Jacinto, Rosa y Margarita, tres pequeños adorables, que a pesar de los disturbios siempre habían mantenido su carácter alegre y receptivo. Pero al verlos con sus brazos maltratados presentí lo peor. 
A la hora del recreo los llamé aparte y les pregunté al respecto.

Es que me caí... -me dijo Margarita.

El cuento de la caída no los convencía ni a ellos mismos, mucho menos a mí, por lo que simplemente me puse de rodillas y los abracé sin decir nada.

Jacinto sacó su cabecita de entre mis brazos y lanzó una mirada altiva hacia otro grupo de niños que se apostaba al lado.

En ese grupo se hallaba Pedro, el hijo del abogado. Al notar Pedro que yo estaba al tanto de ese intercambio de miradas, de inmediato se alejó corriendo, como si se hubiese asustado.

Rosa y Margarita se estrujaban contra mí y sonreían sin tapujos, intentando prolongar aquel abrazo. Aprovechando ese hechizo de amor entre alumnas y maestra, pregunté a las niñas la verdadera razón de los moretones y, casi sin resistencia, respondieron al unísono:

-Fue Pedro, niña, fue Pedro.

Nos pegó a Rosita y a mí y entonces Jacinto quiso defendernos... -agregó Margarita, con la voz entrecortada. ...Y Pedro también lo lastimó...

Apenas terminaron las lecciones, busqué a Pedro y le pregunté sobre los hechos, pero no quiso decir una palabra y se marchó corriendo.

La agresión entre los niños del barrio no sólo era de esperarse, sino que también alimentaba y era alimentada por el conflicto de los adultos y hacía difíciles las alternativas de solución. Además, la reacción agresiva de los chicos ponía de manifiesto la dificultosa situación del barrio, en el que bien que mal todas o casi todas las personas cumplen un papel activo.

Ciertamente, las personas no solo están en la sociedad y ante ella, sino especialmente con ella, coexistiendo, conviviendo.

Ese vivir con los demás es lo que produce la historia.

Reconocer y aceptar "al otro" tiene una doble dimensión que a veces cuesta conjugar. De hecho, el otro se presenta como algo que es propio y la vez representa una dimensión de extrañeza, como algo ajeno.

Por esta razón, "el otro" puede ser, según sea el caso, amigo o enemigo.

Pedro, Jacinto, Rosa y Margarita, en circunstancias diferentes, actuarían como amigos entrañables. Pero en estas circunstancias, inducidas mayormente por sus padres respectivos, son enemigos íntimos y esa enemistad se funda en el reconocimiento de "la otredad", de la diferencia cultural. Pero esa enemistad está tan mediatizada por el entorno y es a la vez tan íntima, que fácilmente puede convertirse en amistad de nuevo.

Por esas razones, cuando finalmente pude conversar con Pedrito y le pregunté sobre lo sucedido, el niño me contestó:

-...Es que Margarita y Rosa me molestan y me dicen cosas feas..., pero a mí no me caen mal...

El niño reflejaba dolor, más que enojo, y frustración, más que prepotencia. Dolor de sentir que la agresión era una respuesta que se imponía sin saber muy bien por qué. Y frustración por no encontrar, precisamente, salidas a un conflicto que no entendía y que era trasladado por sus padres y por los demás adultos.

-Mamá dice que los nicas son gente mala y que siempre han sido malos... -aseveró Pedrito con tristeza.

Yo lo miré dulcemente y lo invité a platicarme sobre sus sentimientos. Aquel estereotipo que la madre de Pedro le inculcaba, me hacía recordar mis años de estudiante de educación y filosofía, porque en aquella época nos centrábamos en los discursos absolutos sobre el bien y el mal.

Todos los lobos y coyotes de Hobbes y los angelitos de Rousseau me invadieron en aquel instante. Pero especialmente recordaba a Spinoza, su reciprocidad de valores y sus signos sinceros del ánimo, que al final me indujo a contestarle a Pedro de la siguiente manera: 
-Los nicaragüenses no pueden ser tan malos si los costarricenses no somos tampoco tan malos.

El niño no entendió inmediatamente el mensaje, tal como le planteé la cuestión, pero después de unos segundos de reflexión me replicó:

-Ah, niña Emilia, entonces, si somos buenos con ellos, ellos serán buenos con nosotros...

Sin esperar otra respuesta de $\mathrm{mi}$ parte, los ojos del niño se iluminaron y se marchó a jugar.

Aquella inferencia del pequeño comprobaba su aguda inteligencia y su especial sensibilidad, pero principalmente daba fe de su potencial espiritual y de la buena voluntad que naturalmente tienen los niños y niñas en sus relaciones.

Por lo demás, la respuesta del chico confirmaba el hecho de que la mayor parte de la agresividad humana se puede rastrear directamente en el sentido de la frustración. Hay quienes afirman que la civilización del niño no puede llevarse a cabo sin frustración de sus necesidades, porque la sociedad insiste en que debe aprender a satisfacerlas en momentos difíciles.

Así, aunque la mayoría de los adultos afrontamos muchas frustraciones en el curso de nuestras vidas, usamos patrones establecidos de reacción para dominarlas y para impedir que vuelvan a presentarse.

No obstante, los niños y niñas no tienen la pericia ni la facilidad de los adultos para remover ni para disimular sus frustraciones. $\mathrm{O}$ al menos eso es lo que queremos pensar.

La frustración, como en el caso de Pedrito, puede aparecer por una discrepancia entre el deseo de resolver un problema y su capacidad para lograrlo.

Pero lo cierto es que interpretar lo que significa la frustración es un asunto personal y depende casi completamente de la percepción que uno tenga de si la recompensa está siendo o no obtenida.
Estos hechos me han enseñado que la frustración que define los conflictos, está determinada por valores marcados por la violencia, que generalmente limitan y distorsionan la percepción, el respeto y la aceptación de las personas entre sí.

Consecuentemente, una solución alternativa del conflicto supone la creación de confianza y credibilidad entre las personas enfrentadas, de modo que la solución surja de los que tienen el problema y no de sujetos externos.

Siguiendo esta lógica, al terminar las lecciones me reuní para conversar en el parquecito con Rosa, Margarita, Pedro y Jacinto.

No voy a reproducir la conversación, principalmente porque los niños y niñas se manifestaron más bien joviales y dispuestos a amigarse nuevamente.

La conciliación entre los chicos marchaba bien, hasta que el padre de Pedro pasó en su vehículo y nos observó. De inmediato detuvo el carro y, vociferando, llamó a su hijo.

Pedrito, temeroso, se puso de pie e intentó correr hacia su padre, pero yo lo detuve y, en su lugar, me dirigí a hablar con el abogado.

-Dígale a mi hijo que venga - sentenció, fuera de sus casillas.

Conservando la ecuanimidad, le respondí:

-Lo siento mucho, pero en este momento estamos trabajando.

$\mathrm{Al}$ hombre se le torcieron los ojos de la cólera y, furioso, me increpó:

-¡Usted no sabe lo que hace! Está abriendo más la herida al juntar a mi hijo con esos güilas — dijo refiriéndose a los niños nicaragüenses.

De seguido continuó:

-Espero que Pedro esté de vuelta en casa en los próximos treinta minutos... De lo contrario...

El hombre no pudo terminar la frase, porque estaba ahogado de ira. Encendió nuevamente el auto y se marchó a toda velocidad. 
Ante esos acontecimientos, inmediatamente después de finalizar la reunión con los niños acompañé a Pedrito a su casa, pero el chico estaba sumamente asustado y, la verdad, yo también me sentía culpable por haber protagonizado ese altercado con su padre.

Caminamos en silencio hasta su casa y llamamos al timbre de la puerta, pero nadie contestó. Llamamos una y otra vez, pero nada. Todo indicaba que en la casa no había nadie.

Finalmente, nos percatamos de que la puerta estaba abierta y se escuchaban voces al interior.

Pedrito estaba más tranquilo y me dijo que se trataba de su madre conversando con otra persona adentro de la vivienda, ante lo cual opté por despedir al chico en la puerta y regresé a la escuela.

El resto de los acontecimientos son la causa de mi permanencia, hoy, en esta celda.

Tres horas después de dejar a Pedrito en su casa, recibí la visita del padre del niño, acompañado por dos policías del Organismo de Investigación Judicial, quienes me mostraron una orden de arresto en mi contra.

Resulta ser que Pedrito desapareció misteriosamente y no ha sido hallado. En su casa encontraron sus zapatos con manchas de sangre y sus cuadernos y libros tirados sobre el piso.

Los policías me mostraron la orden de arresto y ahora me incriminan por la desaparición del niño, quien aparentemente está herido y, lo que es peor, isecuestrado!

Luego de mostrarme la orden, los policías me condujeron hasta esta celda, en donde me mantienen incomunicada.

Por el momento no encuentro claridad sobre los hechos, pero me mantengo esperanzada de que Pedro aparezca sano y salvo.

Un sentimiento de impotencia y angustia me invade, principalmente porque con mi detención me impiden colaborar en la búsqueda del niño.
Este centro de detención es un buen símbolo de mi estado de ánimo: castigada, vigilada e impotente.

El nombre de mi carcelera es Yadira Gómez, "la teniente Gómez", como me ha pedido llamarla. Esta mujer me ha observado compasivamente durante toda la noche, como si entendiera lo que sucede o como si esa luz de comprensión que intento identificar en su mirada, pudiera cubrir todo el espacio y toda la angustia de mi corazón.

\section{Segunda noche}

La teniente Gómez es una mujer extraña. Ella trabaja como carcelera desde las diez de la noche hasta las diez de la mañana y, pareciera ilógico lo que voy a decir, pero lo cierto es que su comportamiento durante la mañana es totalmente diferente del que muestra durante la noche.

Por las mañanas es una persona impostada por su deber policiaco. Se mantiene rígida en su escritorio, efectuando rondas de vez en cuando frente a las celdas de detención, sin hablar mucho con las prisioneras ni atender tampoco sus solicitudes.

A eso de las ocho recibe siempre la visita del fiscal, un tal licenciado Cabra que, dicho sea de paso, el día de hoy me interrogó y, efectivamente, creo que hace honor a su apellido, pues está más loco que una cabra.

Cuando el licenciado llega, la teniente Gómez se postra a su lado y, conduciéndose militarmente, se dirige a las detenidas con voz tirante y seca, dando órdenes por aquí y por allá.

Durante la noche, sin embargo, la teniente se transforma por completo, convirtiéndose en una persona afable y considerada, incluso dulce y atenta a todo cuanto le he relatado de mi historia y de los motivos que me han traído hasta esta celda.

Pareciera ser -sin eliminar la posibilidad de la esquizofrenia- que la teniente Gómez es una buena muestra de la 
asociación y disociación que nos hacen funcionar al margen de la patología y de la "normalidad", aún cuando podamos estar totalmente chiflados, o lo contrario.

Después de escribir durante horas, anoche le conté todo acerca del conflicto en la escuela y la desaparición de Pedro, ante lo cual se mostró muy interesada en conocer los detalles de mi intervención para solucionar el problema.

La teniente puso su silla frente a mi celda y se mantuvo atenta durante largo rato.

Le hablé de Jean Piaget y le fascinó aquello de que el conocimiento es un proceso que se construye y no un estado o un hecho y que sobre esta base también se construye la paz. La teniente estaba extasiada. De pronto sacaba un paquetito de galletas que compartía conmigo y volvía a su actitud expectante, casi infantil.

-Según la teoría operatoria de la inteligencia -le dije, con aire de catedrática- todos los conocimientos provienen de la acción, es decir, de las actuaciones que tenemos sobre los objetos para transformarlos.

La teniente se quedó fría, simulando haber entendido la premisa piagetiana, pero igual se mantuvo atenta a lo que le decía.

-Lo más importante del asunto -continué- es saber que la educación es importante para construir relaciones humanas que sean capaces de enfrentar los conflictos en forma pacífica y productiva. Y también para entender que esas relaciones solamente pueden construirse si transformamos la realidad, si modificamos nuestras relaciones y el mundo que nos rodea, para bien, para mejorar, para buscar la paz.

Aquello de "la paz" le encantaba a la teniente (al menos en su faceta nocturna), que se balanceaba en su silla con gozo.

-Por eso yo voté por Oscar Arias -contestó Yadira, llena de emoción, y agregando: ...Es el presidente de la paz...

La actitud de la teniente respecto de la educación como práctica libertadora me convencía del potencial pedagógico para el cambio de actitudes, que al igual que Freire, años atrás, tenía seguidores importantes entre los intelectuales y políticos. Y ahora entre las carceleras, por supuesto.

Algunos mitos y perversiones de la educación funcionan sobre la base del supuesto carácter homogeneizador del sistema escolar, haciéndonos creer que la escuela tiene la misión y la capacidad de limar las diferencias sociales y culturales.

Pero lo cierto es que la educación que necesitamos debe fomentar el respeto a la diferencia, a la heterogeneidad social y cultural, que debería tener como centro los derechos y las responsabilidades humanas.

El papel educativo de la resolución alternativa de conflictos, que en realidad constituye una educación para la paz, busca precisamente armonizar, no hegemonizar, las diferencias, las personalidades, en un contexto social que nos permita ser solidarias.

Resolver los conflictos no significa, entonces, eliminar las diferencias entre las personas, sino permitir su coexistencia en torno a fines comunes. Para esto tenemos que poner más atención a los problemas y no a las personalidades.

La teniente Gómez me pedía repetir una y otra vez estas ideas, como si tratara de memorizar algunas frases. Luego me solicitó hablarle un poco más de los derechos humanos y de su relación con la educación.

-Los derechos humanos son, como la palabra lo dice, derechos. Pero también pueden considerarse valores -le dije.

Luego continué:

-Los valores son pautas de conducta que, en última instancia, nos indican qué es bueno y qué es malo.

La teniente estaba interesadísima en mi discurso y me alentó a seguir.

-Estos valores tienen un peso muy importante en la educación, porque se supone que los estudiantes deben construir y aplicar el conocimiento que se logra en la 
escuela, basándose en ciertos valores sociales, humanísticos -le dije.

Luego de una pausa continué:

-Según lo anterior, teniente, los derechos humanos entendidos como valores, pueden considerarse como construcciones humanas que nadie está autorizado para violar. Pero los derechos humanos son también leyes concretas, destinadas a proteger a las personas en su dignidad y libertad, contra cualquier ataque que intente lesionarlas.

La teniente Gómez empezaba a impacientarse, porque aún no lograba conectar el discurso sobre los derechos humanos con el problema concreto de la resolución de conflictos y el papel de la educación en todo esto. Aún así, se mantenía atenta a lo que yo le decía.

-No sirve de nada -continué- ensenar a un estudiante las leyes de la naturaleza, la geografía y la matemática, si esa persona va a vivir o a promover un clima de opresión, discriminación y tiranía. Y por eso los derechos humanos, como valores y como leyes, deben ser el fondo común de todo conocimiento y de todo comportamiento.

Resolver los conflictos, por lo tanto -le dije- significa aplicar los derechos humanos para lograr el bien común y la dignidad de las personas.

La conversación con la teniente Gómez buscaba, de mi parte, hacerle ver que las alternativas de solución de conflictos tratan de encontrar maneras creativas de resolverlos sin recurrir a la violencia. De igual forma, quería hacerle ver que la resolución de los conflictos, como práctica educativa, no se dirige únicamente a los estudiantes y las estudiantes, sino también a los adultos, que son sujetos permanentes de la educación.

Nunca se termina de aprender, y por eso la manera de enfrentarse alternativamente a los conflictos supone la capacidad de cambiar actitudes y comportamientos, de modificar valores y de posicionarse frente a la ley de tal manera que los derechos tengan una finalidad siempre constructiva.

Lo alternativo significa el intento de encontrar un sentido diferente a lo que hacemos, y a la manera de enfrentarnos al conflicto. Lo alternativo implica creer en el otro, en la gente y en nosotras mismas y por eso, para que los procesos de resolución de los conflictos lleguen a buen fin, debemos ser siempre estudiantes, es decir, no dejar de aprender de nosotras mismas y de ver el sentido maravilloso que tiene el aprendizaje. Conocernos es una maravilla.

La educación es permanente e involucra a todas las personas, en todas las etapas de la vida y en todas las tareas que realizan.

Este discurso sobre la responsabilidad compartida de todos, tenía francamente confundida a la teniente Gómez.

La mujer se levantaba de su silla y daba vueltas por el pasillo, intentando comprender. De pronto retiraba su revólver del cinturón y se aflojaba la camisa, oxigenando esa manía que tienen los policías de andar siempre tiesos y pulcramente acicalados.

Yo no comprendí la preocupación exacta de la teniente y al principio pensaba que simplemente tenía dificultades para asimilar, tan de pronto, toda la información que le había dado. Obviamente, estaba subestimándola.

De un momento a otro se acercó a los barrotes de mi celda y me preguntó:

-Dígame una cosa, Emilia. Usted dice que para resolver los conflictos todos debemos someternos y participar en las soluciones, ¿cierto?

-Cierto -respondí.

-Entonces -dijo la teniente, confundida-, dígame: ¿para qué sirven los jueces? ¿Para qué sirve la policía?

La interpelación de Yadira me dejó pensativa, pues en efecto, esas preguntas se referían a asuntos básicos de los problemas y limitaciones de la justicia y de las expectativas de la gente, respecto del quehacer de los tribunales y de los jueces. 
Antes de permitirme responderle, la teniente continuó diciendo:

-Y además, Emilia, quiero decirle otra cosa. Usted estaba tratando de resolver un problema entre carajillos nicas y ticos en un barrio de locos. Y..., ¿qué pasó con eso? Resulta que usted terminó arrestada por secuestrar a un mocoso y, de feria, ni siquiera pudo resolver el tanate.

La teniente hablaba sin miramientos, aunque yo tampoco percibía en su actitud ningún ánimo de mortificarme con semejantes aseveraciones. Luego, terminó diciéndome:

-¿No hubiera sido mejor que, en lugar de meterse en ese enredo, usted hubiera llamado a uno de esos centros de conciliación?

-No, teniente, no hubiera sido mejor -le respondí deprisa.

Cuando iba a comenzar a justificar a la teniente Gómez por qué no me parecía conveniente acudir a un centro de conciliación para plantear el conflicto del barrio, la puerta de la sección de celdas se abrió y apareció el licenciado Cabra.

Sin darnos cuenta, nos había sorprendido la mañana conversando.

$\mathrm{Al}$ ver al fiscal, la teniente Gómez volvió a sufrir su cotidiana conversión mañanera e, incorporándose de un brinco para saludar a Cabra, me dejó con las palabras en los labios.

\section{Tercera noche}

El licenciado Cabra pidió a la teniente Gómez abrirle la puerta de mi celda e ingresó rápidamente, como si intentara evitar que yo saliera corriendo.

El fiscal vestía un saco verde con pantalones azules y una corbata de rombos amarillos. Después de auscultarme con su mirada, Cabra sacó de su maletín una libreta y se sentó sobre la cama. Miró a todos lados e inició su interrogatorio:

Doña Emilia: estoy aquí para buscar la verdad real de los hechos por los cuales se le acusa, ¿sabe? Quiero pedirle que me diga toda la verdad, pues la vida de un niño está en juego en este asunto.

El fiscal tosió dos veces y esperó unos segundos antes de continuar.

-Todos sabemos que había sangre en los zapatos de Pedro y que usted fue la última persona en estar con él, así que, dígame la verdad: ¿qué fue lo que pasó?

Yo repetí nuevamente, con lujo de detalles, todo lo que había sucedido, mientras Cabra me miraba fijamente, con ansiosos deseos de inculparme.

Luego de un instante, sentenció:

-Usted debe creer en la justicia. La justicia es buena para todos y aunque a veces comete errores, casi nunca falla, como el Deportivo Saprissa y la Virgencita de Los Ángeles.

Aún no sé si esas comparaciones me provocaron terror o risa, pero lo cierto es que el licenciado Cabra las sostiene con firmeza, pues hablaba con una seriedad inusitada.

$\mathrm{Su}$ creencia en la Corte también es muy cierta, lo cual denota que no ha perdido nunca un caso, o bien que, cuando los pierde, cree ser merecedor de la derrota. Consecuentemente, si estoy en lo correcto, su visión de la justicia, más que real, es formal y por lo tanto bastante artificiosa.

-No sé de cuál justicia me está hablando -le dije. No sé si se justifica tenerme aquí encerrada, mientras Pedro está perdido. Creo que podría ayudar más estando afuera -respondí.

Cabra lanzó una carcajada y replicó:

-Ya veo que usted no cree en la justicia.

Y como si hubiese estado escuchando la conversación que tenía con la teniente Gómez, recalcó:

-De haber creído en la justicia, doña Emilia, usted debió haber sometido el problema con los nicaragüenses a los tribunales, en vez de aventurarse en esos jueguitos de conciliación.

Las palabras de Cabra por poco me sacan de mis casillas, pero pude contenerme antes de contestarle. 
-Los jueces han cambiado mucho -le dije. Ahora, la misma Corte prefiere delegar algunos procesos en las comunidades y en los centros de conciliación, antes que resolverlos en sus despachos.

El fiscal atendió con desconfianza mi mensaje y guardó silencio.

Curiosamente, el interrogatorio sobre la desaparición de Pedro se detuvo, para dar paso a una larga discusión sobre el tema de la administración de justicia, que intentaré reproducir con la mayor objetividad.

El licenciado Cabra se obstinaba en afirmar que la justicia en Costa Rica estaba en las mejores manos. Jueces, fiscales y defensores muy preparados y capaces de brindar un servicio óptimo y etcétera.

Yo no intenté rebatir su posición sobre la base de una crítica a los funcionarios judiciales, sino más bien sobre la función de la judicatura, que se refiere más a la orientación del sistema, antes que al esfuerzo de los que laboran en él.

Le explicaba al licenciado Cabra que la función judicial, en el contexto de la reforma del Estado, ha sufrido modificaciones importantes, inducidas por la globalización de las economías y la contracción y privatización de los servicios públicos.

Estas modificaciones evidencian, le dije, la incapacidad de los tribunales para resolver adecuadamente gran cantidad de demandas de la gente.

-Por ejemplo, licenciado -le recalqué con aire solemne-, el 75\% de las denuncias que llegan a la policía judicial, nunca se resuelven. Y lo que es peor -agregué-: resulta que del 25\% sobrante, sólo una pequeña parte llega a constituir causas que van a juicio. Esto sin contar los casos que tardan diez años antes de obtener una sentencia.

El manejo que tengo sobre estadísticas judiciales pareció incomodar al licenciado Cabra, que optó por mantenerse en silencio, permitiéndome continuar.

El análisis siguiente que arrojé al fiscal se centró en las deficiencias operativas de la administración de justicia, en el carácter selectivo de la acción policial y en las grandes lagunas que existen respecto de la eficiencia judicial.

Estas características permitirían suponer que los procesos de justicia alternativa surgen más por las deficiencias de los tribunales de justicia, que por un sentido de participación comunitaria en la resolución de los conflictos.

En otras palabras, los mecanismos alternos de resolución de conflictos son, en el fondo, una forma de descongestionar la presa de expedientes judiciales y, por lo tanto, revelan la incapacidad funcional del Poder Judicial.

Evidentemente, el problema estriba tanto en las causas que motivan la aparición de la "justicia alternativa", como en los efectos que producen esos mecanismos.

En ese sentido, si bien las causas pueden ser reprochables, los efectos no necesariamente deberían serlo. No obstante, la orientación dispuesta legalmente respecto de los mecanismos de resolución alterna de conflictos, tienen alcances tan limitados y selectivos, que en muchos casos ni siquiera es posible recurrir a los árbitros y mediadores, pues los procesos alternos de negociación, mediación, conciliación y arbitraje, únicamente pueden emprenderse cuando el objeto del procedimiento sean diferencias patrimoniales, es decir, cuando hay plata de por medio.

Esto quiere decir que los diferendos de carácter social, cultural y educativo, no pueden resolverse alternativamente, según la ley costarricense.

Por otra parte, pareciera ser que los mecanismos alternos de administración de justicia, antes que procesos surgidos de las demandas ciudadanas de participación y eficiencia, obedecen a fenómenos estructurales más generales, que tienen que ver con la "informalización" de la administración de justicia.

El fenómeno de la informalidad se ha conocido en el mundo entero, y en especial en Latinoamérica, sobre todo en el 
orden económico, como producto de la reforma y contracción del Estado.

Pero en el caso de la justicia, la informalización de los tribunales ha generado procesos cuasi estatales de administración de justicia, que son realizados por organizaciones de la sociedad civil.

Esta situación pone en entredicho el monopolio de la acción judicial en manos del Estado y podría constituir un portillo a formas espurias para resolver litigios.

El licenciado Cabra estaba asustado al escuchar todo lo que le decía y no fue sino al atender esta última frase, cuando por fin reaccionó:

-No entiendo lo que usted me dice, doña Emilia, a pesar de que habla como abogada y no como maestra. Por un lado pareciera defender la tesis de lograr mayor participación de la gente en la resolución de los problemas. Pero, por otra parte, usted critica el monopolio del Estado en materia de justicia...

Obviamente, Cabra estaba atento a mis palabras y buscaba la forma de pillarme en contradicciones.

-No hay ninguna paradoja -respondí-, y por suerte no soy abogada, aunque sí letrada, como dicen ustedes. Recuerde que una cosa son las causas y otra los efectos. Y el problema se presenta cuando no existe concordancia entre las causas que motivan una acción y sus efectos, como es el caso.

El dilema estriba, ciertamente, en que las circunstancias que motivaron al Estado a promulgar la ley sobre resolución alterna de conflictos, radican más en la incapacidad del Poder Judicial para atender las demandas de la población, que en la necesidad de democratizar la participación de las personas en la resolución de contiendas.

La causa aquí es la estructura deficitaria de los tribunales de justicia, y no la necesidad de promover la paz social.

Por otra parte, los efectos que produce esa ley, tampoco van a tener como consecuencia un aporte significativo en el mejoramiento de la paz social, puesto que los asuntos que se podrían resolver con esos mecanismos, son únicamente los de naturaleza patrimonial y no otros asuntos de fondo, que tienen que ver con la convivencia y con los derechos fundamentales.

Para cuando dije lo anterior, el licenciado Cabra ya se había puesto de pie y se mantenía en un estado de ofuscación inmejorable.

-La historia demuestra que avanzamos, doña Emilia -afirmó con elegancia el licenciado. Y la vida es como un partido de fútbol. A veces se gana y a veces se pierde, pero siempre, señora, siempre se participa en el hermoso juego de vivir.

El símil futbolero ya me tenía harta y, para peores, el licenciado Cabra había entrado en un estado de crisis nerviosa producida por la discusión que sosteníamos, de manera que de un momento su cara se pobló de "tics" que me resultaban sumamente cómicos.

Sus manos temblaban como gelatina, pestañeaba mecánicamente y torcía la nariz con frenesí. Además, hacía circular sus hombros mientras insistía en asemejar la vida con el fútbol y la Corte Suprema de Justicia con el Saprissa.

-Nada de lo que diga podrá ser usado en mi contra -dijo antes de despedirse, como si intentara preservar su orgullo institucional frente a mi diatriba.

-A usted no lo están juzgando -le dije. Pero si de algo le sirve lo que le he dicho, sepa también que espero salir bien librada de todo esto, porque soy inocente.

Cabra sonrió con nerviosismo e insistió, sin explicarse, en que mis puntos de vista son equivocados.

Nuevamente señalé los fundamentos de mis apreciaciones, esta vez con menor ímpetu, intentando demostrarle que el dispositivo institucional costarricense de resolución alternativa de conflictos es ajeno a los principios que teóricamente debería impulsar la conciliación. 
Esos principios parten, en efecto, de que para el análisis y entendimiento de los conflictos, resulta indispensable estudiar las incompatibilidades básicas, es decir, las causas fundamentales que generan un conflicto y lo hacen manifiesto. Y para esos fines, en el análisis de los conflictos es importante estudiar cómo ha sido y cómo se encuentra el nivel de las relaciones entre las partes.

La resolución de los conflictos es por tanto siempre operativa, dialéctica, participativa, flexible y no formal. Debe involucrar directamente a las personas involucradas no sólo en la búsqueda de soluciones, sino especialmente en el análisis del conflicto mismo. De ahí su naturaleza educativa.

Al finalizar mi discurso, el licenciado Cabra estaba a punto de perder la paciencia y la ecuanimidad pues, además, los "tics" nerviosos no lo dejaban respirar normalmente.

Sin aguardar más, pidió que le abrieran la puerta de mi celda y se despidió cortésmente, diciéndome:

-Ha sido un placer visitarla, doña Emilia. Aunque debo confesarle que no hemos avanzado mucho en nuestro caso. De todas formas -agregó- veré que puedo hacer por usted...

Luego de que Cabra se marchó, yo me quedé sola nuevamente, siempre convencida de mi verdad, pero también incómoda, angustiada, de verme bregando contra un sistema irracional y tantas veces absurdo.

Al final, no sé si mi diatriba contribuirá a mi condena o si, por el contrario, la verdad que tanto he defendido "me hará libre".

Cuento las horas y nada sucede. No soy dueña más que de mis propios pensamientos y de mis propios sentimientos. Pero es tan poco lo que puedo alcanzar desde esta celda...

Me queda una satisfacción que se agiganta en mis palabras, pero aún así, después de todo, sigo encarcelada. Sigo presa de mis mejores deseos y de mi esperanza. Después de todo, la vida puede ser un juego...

\section{A la mañana siguiente}

¡Por fin libre! Esta mañana llegó el licenciado Cabra y me entregó un documento del Juzgado, otorgándome la libertad total y sin restricciones.

El fiscal estaba satisfecho, aunque un poco desconcertado (quizás porque tuvo que ofrecerme disculpas en nombre del Poder Judicial).

La situación tuvo un desenlace positivo, aunque no del todo feliz, pues temo que los problemas entre las familias nicaragüenses y ticas continuarán por mucho tiempo. Pero, aún así, todos estos hechos tan dolorosos e intensos me reafirman mi confianza y mi esperanza.

Después de tres noches de incomunicación, la libertad me llegó con una noticia triste.

El mismo día que conduje a Pedrito a su casa, era el padre, y no la madre, quien estaba esperándolo.

Una vez que el niño entró, el padre se abalanzó contra el chico y lo molió a golpes, recriminándole haberse juntado con los niños nicaragüenses.

La paliza fue tan violenta, que las piernas de Pedrito empezaron a sangrar, como consecuencia de los golpes.

Presa del terror, el niño se alejó corriendo de la casa, dejando sus zapatos y sus útiles tirados. Mecánicamente se dirigió hasta la casa de Jacinto, a quien le pidió auxilio.

Después, supimos que no era la primera vez que el padre de Pedro agredía a su hijo y que, en esta oportunidad, la tunda había sido tan salvaje, tan terrible, que el abogado había planeado incriminarme, para así hallar un chivo expiatorio de su indecente conducta.

El niño pidió a Jacinto refugio y éste optó por esconderlo en un rancho que utilizaba con sus amigos para jugar.

Allí estuvo Pedrito por tres noches. Las mismas noches de mi encierro, pero con un dolor mayor que el mío. 
Jacinto se encargaba de dar a Pedro abrigo y comida y esos días les sirvieron para contarse sus vidas, sus problemas y sus sueños.

Muy temprano, esta mañana, la madre de Jacinto encontró a Pedro jugando en el patio de su casa y corrió a dar noticia a la delegación de la policía.

Por mi parte, una vez que quedé en libertad, corrí hasta la escuela y me encontré, en el salón de actos, con una reunión multitudinaria de padres y madres de familia, ticos y nicas, todos reunidos.

Cuando entré la gente se mantuvo en silencio, como si estuvieran avergonzados de lo sucedido, o más bien aliviados por la aparición de Pedro. No obstante, nadie dijo nada, hasta que llegué a la mesa donde se hallaba el director junto con otras compañeras.

El director me dio un abrazo caluroso y sin poder agregar más, dijo a la concurrencia:

-Démosle la bienvenida a la niña Emilia.

Buena parte del público se levantó y me aplaudió de pie, en un gesto que me conmovió profundamente. Otra parte se mantuvo sentada, sin mostrar especial sorpresa ante mi aparición.

A un lado del salón estaban Jacinto, Rosa, Margarita, Pedro y otros chicos de mi grupo, quienes me saludaban de puntillas, levantando sus brazos al aire.

Me miraban con una sonrisa mágica en el rostro, intentando adivinar la reacción que tendría con ellos y ellas.

Por primera vez, desde hace días, no pude decir nada, quizás porque no me tocaba hablar esta vez a mí.

Había tanta gente allí reunida, dispuestas a escuchar y a decir sus propias verdades, que lo único que tenía sentido era mirar los ojos de los niños, todos juntos, esperando que sus padres dejaran fluir sus pensamientos para construir sus sentimientos.

No sé si lograremos un acuerdo hoy o mañana o dentro de un año. No sé si llegaremos a soluciones fáciles o difíciles. Pero estamos todos aquí y eso es una gran victoria, porque hemos comenzado a comprender que el bienestar propio empieza en el bienestar de la otra gente.

Por mi parte, esto es todo lo que aguanta este cuaderno. Ahora voy a arrojarlo en el basurero más cercano y pondré manos a la obra.

\section{Referencias bibliográficas}

Bernardini, Amalia y Soto, José Alberto. La Educación actual en sus fuentes filosóficas. EUNED, San José, 1997.

Coser, Lewis. Nuevos aportes a la teoría del conflicto social. Amorrortu. Editores. Buenos Aires, 1970.

Gutiérrez, Francisco y Prieto, Daniel. La mediación pedagógica para la educación popular. Radio Nederland Training Centre. San José, 1994.

Filley, Alan. Solución de conflictos interpersonales. Editorial Trillas. México, 1985.

Freire, Paulo. Pedagogía de la esperanza. Siglo XXI Editores. México, 1996.

Instituto Interamericano de Derechos Humanos. Resolución Pacífica de Conflictos. Módulo 3. Instituto Interamericano de Derechos Humanos, San José, 1997.

Instituto Interamericano de Derechos Humanos. Memorias del Taller sobre mecanismos alternativos para la resolución de conflictos. Instituto Interamericano de Derechos Humanos, San José, 1996.

Instituto Interamericano de Derechos Humanos. Serie: Educación y Derechos 
Humanos. 1. Temas introductorios. Instituto Interamericano de Derechos Humanos, San José, 1988.

Ley sobre resolución alterna de conflictos y promoción de la paz social. Número 7727 del 9 de diciembre de 1997.

Magendzo, Abraham. Dilemas y tensiones en torno a la educación en derechos humanos en democracia. En: Revista del Instituto Interamericano de Derechos Humanos. Número 14. Julio-diciembre de 1991.

McNeil, Elton et al. La naturaleza del conflicto humano. Fondo de Cultura Económica. México, 1975.

Ortega Pinto, Herbert. La teoría del conflicto y la resolución de conflictos. Universidad para la Paz. Ciudad Colón, 1996.

Paniagua, Alvaro y Muñoz, Vernor. Impunidad, denuncia y policía judicial. Defensoría de los Habitantes de la República, San José, 1996.
Pérez Córdoba, Rafael y otros. Los procesos de enseñanza y aprendizaje en una sociedad democrática. Ministerio de Educación Pública, San José, 1991.

Piaget, Jean. Psicología y espistemología. EMECE editores. Buenos Aires, 1992.

Picado, Sonia. La fundamentación histórica, filosófica y jurídica de los derechos humanos. Instituto Interamericano de Derechos Humanos, San José, 1986.

Puigrós, Adriana. Discusiones sobre educación y política. Editorial Galerna, Buenos Aires, 1987.

Rojas Díaz, Everardo. Introducción a la resolución alternativa de conflictos. Servicio de Paz y Justicia, Costa Rica. San José, 1997.

Varios Autores. Estudios sociológicos sobre sociología del conflicto y la cooperación. Universidad de Veracruz. México, 1965.

Varios Autores. Sobre el Contrato Social. Editorial Libro Libre. San José, 1987.

Vernor Muñoz Villalobos Funcionario de la Defensoría de los Habitantes de la República 